\title{
Protocol to Evaluate Antibacterial Activity MIC, FIC and Time Kill Method
}

\author{
Fadwa Alshareef* \\ Department of Clinical Laboratory Science, College of Applied Medical Science, \\ King Saud University, Riyadh, K.S.A \\ *Corresponding Author: Fadwa Alshareef, Department of Clinical Laboratory \\ Science, College of Applied Medical Science, King Saud University, Riyadh, K.S.A \\ Email:fadoalshareef@ksu.edu.sa
}

Received: March 03, 2021

Published: April 01, 2021

(C) All rights are reserved by Fadwa Alshareef.

\section{Introduction}

In the evaluation of antibacterial activity using various antibiotics and ZnoNPs nanoparticles alone and in combination, microdilution broth, checkerboard techniques and time kill curve assay are commonly used. Checkerboard data analysis depends on different mathematical and pharmacological models to detect deviations from theories of no-interaction and to evaluate antagonistic and synergistic interactions [1]. In vitro antimicrobial drugs formulations in combinations are generally assessed by fractional inhibitory concentration (FIC) index which denotes the sum of the FICs of each formulated drug tested, whereas, FIC is evaluated for each formulated drug by dividing the MIC of each formulated drug and used in combination by the MIC of each formulated drug used alone. FIC index is based on Loewe additivity zero interaction theory [2], based on the hypothesis that a drug cannot interact by itself and the effect of a self-drug combination will be additive, with an FIC index of 1, therefore, FIC index lower or higher than 1 indicates synergy or antagonism, as less or more drug would be required in order to have the same effect as the drugs alone [2].

Because of the twofold drug dilution scheme and the 1-dilution error of single-drug susceptibility testing methods used for FIC index determination, cutoffs of 0.5 and 4 were suggested for defining additivity/indifference. However, the actual variation of the FIC index in checkerboard microdilution methods was not well studied. In addition, most in vitro combination studies resulted in FIC indices within the range of 0.5 to 4 concluding no interaction (additivity/indifference), raising questions about the validity of this arbitrarily chosen FIC range given the absence of in vitro-in vivo correlation studies.

\section{Bacterial suspension preparation}

- The bacterial culture suspension must be prepared according to Clinical Laboratory Standards Institute (CLSI) guidelines [3], both positive and negative controls were used the positive control was used to test the growth conditions of bacteria and the negative control to check sterility of the media.

- Isolates that showed resistance or elevated MIC were kept for further investigation, stored at $-80^{\circ} \mathrm{C}$ in skim milk media with glycerol.

- To test the MIC values against the antibiotics (e.g. Meropenem, Ciprofloxacin or Colistin etc) subcultures of isolates were revived by streaking on Blood/Nutrient agar plates, and incubated overnight at $37^{\circ} \mathrm{C}$ and $5 \% \mathrm{CO}_{2}$ incubator.

- To prepare the colony count to approximately $5 \times 10^{5} \mathrm{CFU} /$ $\mathrm{mL}$ (CLSI, 2012), a direct saline suspension of isolated colonies selected from an 18 - 24 hour incubated blood/Nutrient agar plate was prepared. Then, the turbidity of this suspension was adjusted using a McFarland turbidity reader, equivalent to a 0.5 McFarland standard.

- This saline suspension was diluted 1:20 times in Muller Hinton Broth (MHB) ready-made liquid broth medium, by adding $100 \mu \mathrm{L}$ of the saline suspension to a tube containing 1900 $\mu \mathrm{L}$ MHB, immediately before using it.

- $10 \mu \mathrm{L}$ of the bacterial suspension was inoculated in wells containing $100 \mu \mathrm{L}$ of the antibacterial agent, that is, the volume of the suspension was $10 \%$ of the final volume in each microtiter well [4]. 
Antibacterial agent and zinc oxide nanoparticles (ZnO NPs) preparation

Pure powdered antibiotics (e.g. Meropenem, Ciprofloxacin or Colistin etc) can be used as antibacterial agents.

First the antibiotic stock solutions would be prepared, by accurately weighing and dissolving in the appropriate diluents to yield the required concentrations.

The following formulas could be used to determine the amount of powder (1) or diluent (2) to make standard solution:

- Weight $(\mathrm{mg})=$ Volume $(\mathrm{mL}) \cdot$ Concentration $(\mu \mathrm{g} / \mathrm{mL}) /$ Potency $(\mu \mathrm{g} / \mathrm{mg})$

- Volume $(\mathrm{mL})=$ Weight $(\mathrm{mg}) \bullet$ Potency $(\mu \mathrm{g} / \mathrm{mg}) /$ Concentration $(\mu \mathrm{g} / \mathrm{mL})$

To determine the powder weight required, we used the formula:

$\mathrm{W}(\mathrm{mg})=[\mathrm{V}(\mathrm{mL}) \times \mathrm{C}(\mu \mathrm{g} / \mathrm{mL})] / \mathrm{P}(\mu \mathrm{g} / \mathrm{mg})$

Where $\mathrm{W}=$ Weight of antibiotic powder, $\mathrm{V}=$ Volume of the diluent, $\mathrm{C}=$ Concentration of stock solution, and $\mathrm{P}=$ Potency of the antibiotic [4].

Antibiotic stock solution would be prepared as follows:

- Meropenem trihydrate by dissolving $1600 \mu \mathrm{g}$ of the antibiotic dissolved in $1 \mathrm{~mL}$ Dimethyl sulfoxide (DMSO) and the concentration will be $1600 \mu \mathrm{g} / \mathrm{mL}(1.6 \mathrm{mg} / \mathrm{mL})$.

- Ciprofloxacin stock solution was prepared by dissolving $1600 \mu \mathrm{g}$ of the antibiotic in $1 \mathrm{~mL} 0.1 \mathrm{~N} \mathrm{HCL}$, and the concentration will be $1600 \mu \mathrm{g} / \mathrm{mL}(1.6 \mathrm{mg} / \mathrm{mL})$.

- The Colistin is completely soluble in water, the Colistin stock solution was prepared by dissolving $3200 \mu \mathrm{g}$ (3.2 mg) of the antibiotic in $1 \mathrm{~mL}$ sterile distilled water, and the concentration will be $3200 \mu \mathrm{g} / \mathrm{mL}$.

- The $\mathrm{ZnO} /$ water suspension could be prepared by weighing $16 \mathrm{mg}$ of $\mathrm{ZnO}$ nanoparticles in $1 \mathrm{~mL}$ of sterile distilled water and the suspension must be subjected to vigorous vortex.

- $\quad$ Suspending the ZnO NPs by sonication at different voltages could be attempted.

- However, after comparing the results it was found that better results were obtained by non-sonicated $\mathrm{ZnO}$ /water suspension, and that the ZnO NPs were well dispersed in the water.
Minimum inhibitory concentration (MIC)

- The broth microdilution method is used to determine Minimum Inhibitory Concentration (MIC).

- Costar 96-well Polystyrene Cell Culture Cluster with flat bottom plate would be used for the experiment, antibiotic susceptibility testing results (if susceptible, intermediate, or resistant), were determined using MIC value breakpoints [3].

- To the microtiter plate $100 \mu \mathrm{L}$ of Mueller Hinton Broth (MHB) would be added from column one to column twelve.

- The antibiotic stock solution prepared in section 3 stored at $-20^{\circ} \mathrm{C}$ must be thawed and diluted to $1 / 100$ in a tube containing MHB and add $20 \mu \mathrm{L}$ of the stock solution to $1980 \mu \mathrm{L}$ MHB and the concentration would be $16 \mu \mathrm{g} / \mathrm{mL}$.

- $200 \mu \mathrm{L}$ of the above dilution must be added to all the wells of the first column in the microtiter plate and then double dilute by taking $100 \mu \mathrm{L}$ from the first to the second column using the multichannel pipette and mix properly.

- Lastly, $10 \mu \mathrm{L}$ of the bacterial suspension must added to all columns except negative control.

- Negative control contains only $100 \mu \mathrm{L}$ MHB and positive control contains MHB and bacterial suspension [4].

- MIC would be determined by comparing the growth rate of tested bacterial strains with the positive and negative controls.

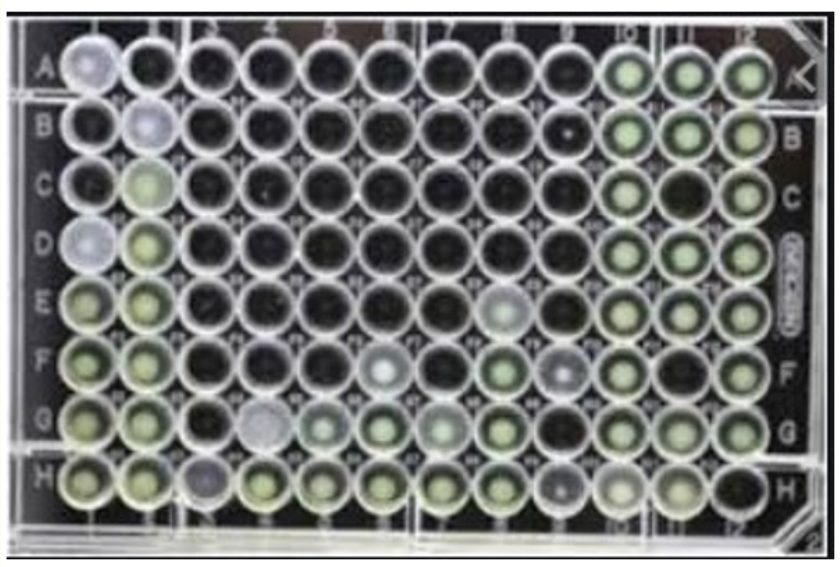

Figure 1: Microdilution broth plate 96 well. 


\section{Checkerboard method}

The checker board method used to evaluate the interaction between the antibiotic or drug formulations (Meropenem, Ciprofloxacin and Colistin) and the ZnO NPs.

Procedure to prepare the checkerboard plate

- The antibiotic stock solution stored at $-20^{\circ} \mathrm{C}$ should be taken out and thawed.

- The stock solution was diluted $1 / 100$ in a tube containing MHB by adding $40 \mu \mathrm{L}$ of the stock solution to 3960L of MHB and the concentration would be $16 \mu \mathrm{g} / \mathrm{mL}$.

- Arrange eight tubes in a rack and add $2 \mathrm{~mL}$ MHB.

- The antibiotic concentration $(16 \mu \mathrm{g} / \mathrm{mL})$ would be double diluted by adding $2 \mathrm{~mL}$ in a tubes containing $2 \mathrm{~mL}$ MHB and the concentration would be $8 \mu \mathrm{g} / \mathrm{mL}$ and the process must be repeated to get the final concentration to $0.06 \mu \mathrm{g} / \mathrm{mL}$.

- $100 \mu \mathrm{L}$ of the antibiotic concentration (16 $\mu \mathrm{g} / \mathrm{mL})$ would be added to all the wells in column of microtiter plate.

- The process must be repeated for the rest of the dilutions, moving across the columns from the highest to the lowest concentration.

For the ZnO NP suspension the following steps were carried out

- Initially, the tubes filled with $1 \mathrm{~mL}$ sterile water must be arranged in a rack.

- $\quad$ Next, $1 \mathrm{~mL}$ of the stock $\mathrm{ZnO}$ /water suspension must be added to the first tube and double diluted with water till reach the last tube.

- And $1 \mathrm{~mL}$ of MHB must be added to each tube to support the growth of the bacteria.

- The concentration in first tube would be $4 \mathrm{mg} / \mathrm{mL}$.

- The microtiter plate that already contained the antibiotic solutions were filled with $100 \mu \mathrm{L}$ solution from the above first tube prepared.

- Similar process must be followed for the second concentration also filling the next row till the final concentration, microtiter plate would be having a decreasing concentration of the antibiotic in the horizontal direction against a decreasing concentration of the ZnO NPs in the vertical direction.

- The bacterial suspension $20 \mu \mathrm{L}$ was added to the whole microtiter plate column except the negative control.
- Mixing must be done at each step using the multichannel pipette using sterile tips.

- All the plates must be was incubated $37^{\circ} \mathrm{C}$ in incubator, and optical density (OD) of themicroplate must be read before incubation using a microplate spectrophotometer (SpectraMax Plus 348) from Molecular Devices at a wavelength equal to $600 \mathrm{~nm}$ and after incubation for overnight the optical density (OD) must be taken at $600 \mathrm{~nm}$.

- The microtiter plate could be incubated for 16 hours in the SpectraMax machine which automatically read the OD every five minutes and plotted the growth curve with the SoftMax Pro Software.

- MIC for the antibacterial agents/drugs could be determined by comparing the growth of tested bacteria strains with positive and negative controls, experiment must be performed three times for each bacterial strains.

The following equation was used to calculate FICI:

$\mathrm{FICI}=\mathrm{FICAb}+\mathrm{FICNP}$

Where, FIC antibiotic $=($ MIC of Antibiotic in the presence of nanoparticle) $/$ (MIC of antibiotic alone) and FIC nanoparticle $=($ MIC of nanoparticle in the presence of antibiotic)/(MIC of nanoparticle alone).

FICI value interpretation ranges as follows: FICI is less than or equal to 0.5 is consider as synergy and more than 4.0 it is considered as antagonism. If FICI in between $>0.5$ and $\leq 1.0$ consider as an additive and FICI between $>1$ and $\leq 4.0$ is consider as indifference.

\section{Time-Kill method}

The time-kill method is used to test the bactericidal activity of one or more antimicrobial agents against a particular bacterial strain. This is done by counting viability of bacterial strains at different time intervals. The experiment would be performed in a 96-well microtiter plate.

To obtain the time-kill curve the bacterial strains growth rate must be counted at different time intervals starting from 0 hours to 24 hours, and these time intervals are plotted as a semi-log plot or graph. The bacterial strains would be usually plotted on the ordinate ( $\mathrm{Y}$ axis) in logarithmic scale while the corresponding time is on the abscissa ( $\mathrm{X}$ axis) in arithmetic scale. 
The Microtiter plate for the time-kill method contained the antibiotic alone in one row (row A), the ZnO NPs suspension alone in another row (row $\mathrm{C}$ ), and the combination of these two agents in a separate row as well (row B). To prepare the microtiter plate, first, the antibiotic MIC for the tested strain was determined as described in section 4 .

The stock solution of selected antibiotic was diluted to four times the MIC $(4 \times$ MIC) for tested bacterial strains.

The serial double dilutions of would be done by adding $0.5 \mathrm{~mL}$ MHB and $0.5 \mathrm{~mL}$ of the previous concentration which will be equal to double the MIC $(2 \times$ MIC $)$.

In one row of each well $200 \mu \mathrm{L}$ of the decreasing concentrations of the antibiotic solution will be added as $(4 \times \mathrm{MIC}),(2 \times \mathrm{MIC})$ and (MIC) concentration.

In another row of the well add $100 \mu \mathrm{L}$ of antibiotic concentration $(4 \times \mathrm{MIC}, 2 \times \mathrm{MIC}$, and MIC).

In some cases half the MIC and quarter the MIC $(0.5 \times$ MIC, $0.25 \times$ MIC) could also be added.

\section{Time kill growth curve for ZnO NP suspension}

- The stock $\mathrm{ZnO} /$ water solution prepared in the above previous section would be used.

- For serial dilution the tubes would be arranged `containing $0.5 \mathrm{ml}$ sterile water.

- The Different concentrations would be prepared by double dilution technique, by adding $0.5 \mathrm{~mL}$ of $\mathrm{ZnO}$ stock solution to $0.5 \mathrm{ml}$ of sterile water and process would be repeated by transferring $0.5 \mathrm{ml}$ to the next tubes to get the desired concentration of (MIC).

- To support the bacterial growth of bacteria $0.5 \mathrm{~mL} \mathrm{MHB}$ was added to each tube, the desired concentration would be in decreasing order as follows, equal to four times the MIC $(4 \times \mathrm{MIC})$, tdouble the MIC $(2 \times \mathrm{MIC})$, MIC concentration (MIC),half the MIC $(0.5 \times \mathrm{MIC})$ and quarter the MIC $(0.25 \times \mathrm{MIC})$.

- For the microtiter plate assay the protocol must be followed.

- Add $100 \mu \mathrm{L}$ of antibiotic solution to the wells filled with 100 $\mu \mathrm{L}$ of $(0.5 \times \mathrm{MIC}) \mathrm{ZnO}$ NP suspension.

- Then the next rows would be filled with $200 \mu \mathrm{L}$ of ZnO NPs decreasing concentration suspensions prepared above.
- The positive control must contain $200 \mu \mathrm{L}$ of the MHB and the bacterial suspension and the negative control with 200 $\mu \mathrm{L}$ of the MHB.

- To all the wells $20 \mu \mathrm{L}$ of the prepared bacterial suspension were added, except for negative control and then incubate at $37^{\circ} \mathrm{C}$ in a $5 \% \mathrm{CO}_{2}$ incubator.

For colony counting assay the following steps must be performed:

- First $10 \mu \mathrm{L}$ of the suspension were aspirated from each well at different time intervals starting from 0hours to 24 hours during the incubation period and diluted to 1:10 in PBS and diluted samples were streaked on blood agar plate and the plates were incubated for 24 hours in a $\mathrm{CO}_{2}$ incubator at $37^{\circ} \mathrm{C}$.

- After incubation the colonies were counted and the data must be recorded in an Excel sheet and the graph of time-kill curve as semi-log plot would be plotted, to get the plot the colony counts as a Log10 of the CFU/mL would be on the $\mathrm{Y}$ axis in the logarithmic scale and the time on the $\mathrm{X}$ axis in arithmetic scale.

- Bacteriostatic activities are defined as $<3 \log 10$ and bactericidal activities are defined as $\geq 3 \log 10$ reductions in CFU/ $\mathrm{mL}$ during the incubation period of 24-hours (CLSI, 1999).

- Synergy values are $\geq 2 \log 10$ decrease in CFU.

- Indifference is defined as $\leq 1 \log 10 \mathrm{CFU} / \mathrm{mL}$.

- $\quad$ Additive is $<2 \log 10 \mathrm{CFU} / \mathrm{mL}$.

\section{Conclusion}

As the combinations of drug therapy is being practiced in the laboratories to evaluate the efficacies of drugs and their combinations to check the sensitivity of the bacterial and fungal strains, the mentioned protocols of MIC and FICI could be valuable.

\section{Acknowledgement}

The authors acknowledge the support of grant from the "Research Center of the Female Scientific and Medical Colleges", Deanship of Scientific Research, King Saud University for supporting this research project. 


\section{Bibliography}

1. Eliopoulos G and R C Moellering Jr. "Antimicrobial combinations". In V Lorian (ed.), Antibiotics in laboratory medicine. The Williams and Wilkins Co., Baltimore, MD (1996): 330-39.

2. Berenbaum M C. "What is synergy?" Pharmacology Review 41 (1989): 93-141.

3. Wayne PA. Clinical and Laboratory Standards Institute. "Performance standards for dilution antimicrobial susceptibility tests for bacteria that grow aerobically". 11th ed CLSI standard M07 Clinical and Laboratory Standards Institute (2018).

4. Wayne PA. "Methods for Dilution Antimicrobial Susceptibility Tests for Bacteria That Grow Aerobically". Clinical and Laboratory Standards Institute Approved Standard-Ninth Edition, M07-A9 (2012).

\section{Assets from publication with us}

- Prompt Acknowledgement after receiving the article

- Thorough Double blinded peer review

- Rapid Publication

- Issue of Publication Certificate

- High visibility of your Published work

Website: www.actascientific.com/

Submit Article: www.actascientific.com/submission.php

Email us: editor@actascientific.com

Contact us: +919182824667 